\title{
Entre kronos e kairós: o sentido e as implicações da ampliação do tempo de permanência dos estudantes na escola
}

\section{Between kronos and kairós: the meaning and implications of extending school time for students}

\author{
Marília Andrade Torales ${ }^{1}$
}

\begin{abstract}
RESUMO
Este artigo apresenta um recorte dos resultados de uma pesquisa desenvolvida nacionalmente - Educação Integral em Tempo Integral no Ensino Fundamental: Concepções e Práticas na Educação Brasileira - que analisou as experiências de ampliação da jornada escolar em diferentes regiões do Brasil. Nesse contexto, a análise das experiências escolares desenvolvidas nos estados do Rio Grande do Sul, Santa Catarina e Paraná foi a base que permitiu estabelecer um diálogo entre empiria e teoria para a compreensão dos sentidos e das implicações do uso e da ampliação do tempo educativo escolar. Neste diálogo, procuramos compreender o impacto provocado pelas modificações na jornada escolar tradicional, de quatro horas diárias, sem a participação efetiva e constante de outros agentes formativos. $\mathrm{O}$ processo de análise dos dados tratou de identificar as mudanças na organização e no funcionamento das escolas, bem como na relação dessas com suas comunidades. Mais do que pensar em horários e rotinas, buscou-se pensar em horas concretas, em períodos de permanência dos estudantes nas comunidades escolares e no sentido que essa presencialidade adquire para os envolvidos nesse processo e para a própria sociedade.
\end{abstract}

Palavras-chave: educação em tempo integral; região sul do Brasil; jornadas escolares.

1 Doutora em Ciências da Educação pela Universidade de Santiago de Compostela (Espanha). Professora Adjunta da Universidade Federal do Paraná (UFPR), Brasil. E-mail: marilia. torales@ufpr.br. 


\begin{abstract}
This article presents part of the results of a research developed at national level - Full-time Complete Education in Primary School: Conceptions and Practices in Brazilian Education - which analyzed the experiences of extending the school time in different areas of Brazil. In this context, the analyses of the school experiences developed in the states of Rio Grande do Sul, Santa Catarina and Paraná were the basis which enabled a dialogue between empiricism and theory in order to comprehend the meanings and implications of the use and extension of educational school time. In this dialogue, we sought to understand the impact caused by the modifications in traditional school time, which is of four daily hours and without the effective and constant participation of other forming agents. The process of data analysis identified the changes in the organization and functioning of schools, as well as in the relationship with their communities. More than thinking of schedules and routine, the work thought of concrete hours, of periods when students stay in the school communities and of the meaning represented by this presence to the people engaged in this process and to our society itself.
\end{abstract}

Keywords: full-time education; southern Brazil; school time.

As figuras mitológicas de kronos e kairós são lembradas aqui para representar um processo de análise que pretende compreender o sentido e as implicações da ampliação das jornadas escolares no contexto brasileiro, em especial nas experiências que se desenvolvem na região sul. Trata-se de um tema complexo, permeado pelas circunstâncias sociais em que as famílias vivem e educam seus filhos e filhas. Ou seja, um debate que precisa ser posto a toda sociedade e mediado pelos responsáveis pelo planejamento e efetivação das políticas públicas, já que o tempo escolar ocupa um espaço significativo na vida de crianças e adolescentes, condicionando à rotina familiar as possibilidades de convívio no tempo extraescolar. Segundo nossa atual legislação, o tempo destinado a educação escolar deverá corresponder a um mínimo de quatro horas diárias, distribuídas em duzentos dias letivos. Portanto, horários e calendários escolares materializam intenções político-ideológicas, compõem os traços identitários da cultura pedagógico-escolar e se inscrevem no conjunto dos tempos de existência do ser humano em sociedade.

O controle do tempo converteu-se em um dos grandes reguladores da existência humana e na contemporaneidade essa condição toma contornos cada vez mais nítidos, em especial no que se refere à organização do trabalho e ao convívio social. A conciliação entre as diversas temporalidades cotidianas se impõe, cada vez mais, como um desafio para a maioria das pessoas que necessitam cumprir suas funções familiares, pessoais e profissionais. Nessa tessitura, o conjunto dos tempos sociais, educativos e, em particular, dos tempos educativo-escolares 
adquirem um protagonismo especial, ainda mais para países como o Brasil, que vive uma fase de mudanças em seu padrão de desenvolvimento e que demanda rápida melhora nos resultados de aprendizagem de sua população escolar.

Mais do que pensar em horários, nos propomos, através desta reflexão, a pensar no uso e no sentido concreto do tempo educativo, nos períodos de permanência dos estudantes nas comunidades escolares e nas implicações que essa presencialidade adquire para os envolvidos nesse processo. Nesse diálogo com o campo empírico, tendo como base a coleta de dados oriundos de três diferentes experiências de ampliação da jornada escolar no sul do Brasil, tratou-se de identificar o impacto provocado pelas modificações na jornada escolar de quatro horas diárias, as decorrentes mudanças na organização e funcionamento das escolas, bem como na relação dessas com suas comunidades.

Resumir o debate sobre o uso do tempo escolar a uma simples revisão de horários, rotinas ou calendários escolares seria reduzir as possibilidades de compreensão da realidade, pois o processo educativo-escolar envolve uma maior amplitude de questões que precisam ser aprofundadas nas políticas públicas de educação e no próprio cotidiano das instituições. Assim, e com intuito de enriquecer o debate, a figura 1 toma por nexo uma tentativa de esquematizar os elementos que compõem a complexidade de relações estabelecidas a partir das experiências de ampliação da jornada escolar nas diferentes propostas de educação em tempo integral analisadas.

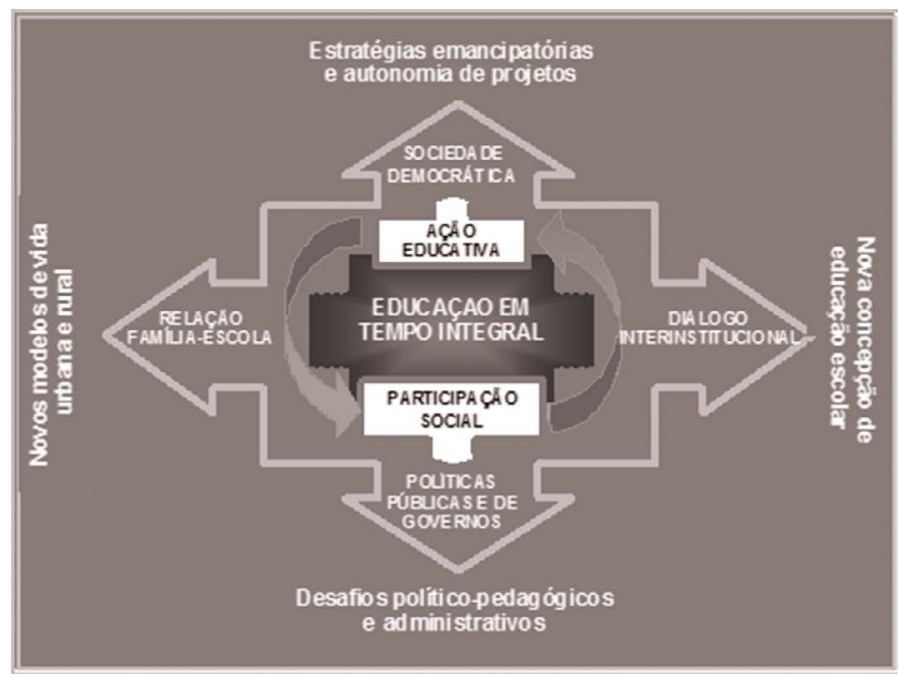

FIGURA 1- IMPLICAÇÕES SOBRE O USO E A AMPLIAÇÃO DO TEMPO EM EDUCAÇÃO ESCOLAR FONTE: Elaborada pela autora 
Distribuir elementos dinâmicos em uma estrutura estática não se constitui em uma tarefa fácil, mas esse esforço se justifica pela possibilidade de construir um esquema que possibilite compreender a amplitude das questões relacionadas ao uso e à ampliação do tempo de permanência dos estudantes do ensino fundamental nas escolas públicas brasileiras. Mais concretamente, desde uma ótica sociológica e/ou pedagógica, a análise do plexo que envolve a definição das propostas escolares para o "preenchimento" da jornada escolar ampliada forja-se no debate sobre o próprio sentido da instituição escolar, considerando suas necessidades, logros e deficiências para educar e socializar crianças e adolescentes.

Ao assumir que a ação escolar objetiva a formação de cidadãos capazes de agir e garantir a manutenção de contextos sociais democráticos seria preciso pensar nas necessidades estratégicas que permitiriam lograr essa expectativa. Sobre isto, nos referimos às opções que precisam e estão sendo feitas em relação ao uso do tempo ampliado nas escolas. Nesse sentido, mais que indicar um terreno de floresceres de sucessos, caberia sublinhar que as mesmas escolas, que muitas vezes manifestam fortemente suas incertezas e fragilidades em relação às demandas educativas mínimas, estão assumindo novos desafios organizativos e estruturais.

Em concreto, a autonomia na elaboração de projetos escolares para cumprir as demandas de ampliação do tempo de permanência dos estudantes nas escolas tem sido um espaço de criação a partir dos interesses e possibilidades dos professores e das escolas, no entanto, seria preciso avançar para a construção de propostas pedagógicas em que os tempos intraescolares não se fragmentassem em "momentos de estudo" e "momentos de atividades alternativas, esportivas, artesanais ou recreativas", ou em pior hipótese, mas de forma recorrente na fala de estudantes, professores e familiares, em um "momento de estudo" e em um "momento de reforço e repetição do "momento de estudo".

Neste momento, inúmeras comunidades escolares enfrentam o desafio de propor estratégias emancipatórias e integradoras entre os diferentes tempos de permanência dos estudantes no contexto escolar, o que as leva, muitas vezes, a repensar o próprio sentido da escola, já que a educação em tempo integral promove a integração de diversos novos sujeitos e instituições ao cotidiano escolar.

A participação de outras instituições na proposta educativa das escolas e a precariedade de muitos aspectos das escolas públicas nos leva a pensar que o deslocamento de estudantes até determinados espaços ou a presença de outros agentes no espaço escolar pode ser considerado como um elemento positivo. No entanto, essa dinâmica não diminui a necessidade de melhorias físicas e materiais

2 Entenda-se por "momento de estudo", o período em que os estudantes realizam atividades relacionadas ao desenvolvimento de conteúdos e habilidades escolares, descritas em representações cotidianas de uma sala de aula. 
coerentes com a realidade das unidades escolares. Como exemplo, não seria lógico a aquisição de instrumentos musicais sofisticados em escolas pequenas, sem estrutura acústica mínima ou um profissional especializado para orientar o aprendizado dos estudantes. Se outros agentes participam da ação educativa escolar, seria coerente considerar que a escola também participa de outras ações fora de seu âmbito e sobre elas exerce influências, ao mesmo tempo em que também é influenciada. Ou seja, se existe uma ação educativa com outras instituições, também é preciso considerar a necessidade de estabelecimento de diálogo entre as propostas pedagógicas das escolas e as instituições parceiras ou colaboradoras.

\section{Se a "ampliação da jornada escolar" é a resposta, qual foi a pergunta? Al- gumas reflexões e hipóteses}

Muitas vezes, mais do que conhecer as respostas, valeria indagar qual foi a pergunta que lhes gerou e lhes deu sentido. Nesse caso, se a ampliação da jornada escolar pode ser considerada como uma resposta a determinado contexto, qual seria a pergunta ou contexto que a gerou? Sem a pretensão de limitar ou esgotar esse debate, gostaríamos de aprofundar algumas hipóteses que emergem da análise do contexto e da dinâmica social, apresentando-se de forma insistente em diferentes discursos individuais ou institucionais.

Hipótese 1: Como a escola poderia atender as necessidade das famílias contemporâneas, que baseiam seu sustento na renda gerada por pais e mães trabalhadores?

Hipótese 2: Como se poderia melhorar o rendimento escolar dos estudantes que frequentam as redes públicas de ensino e atender a uma demanda de desenvolvimento econômico-social?

Hipótese 3: O modelo tradicional de escola tem sido questionado desde diversas perspectivas, por pesquisadores, professores, estudantes, familias, ou mesmo, pela sociedade em geral. Quais seriam as estratégias possíveis para repensar esse contexto e a própria função social da escola?

Assim, com base nessas questões, o aumento do tempo de permanência dos estudantes nas escolas, como possível resposta, demanda um fortalecimento das instituições escolares e uma ressignificação social de seu papel. Trata-se de analisar cada realidade na busca de alternativas viáveis e pertinentes para questões de ordem estrutural, organizativa e pedagógica, necessariamente, ou de melhor maneira, construídas de forma participativa e com a definição de responsabilidades.

Nesse sentido, a conciliação entre a disponibilidade de horários das escolas e das famílias é uma questão a ser mediada pelas instâncias político-administrativas do poder público, pois as responsabilidades dos profissionais 
da educação com a escola têm seus limites. Mais além, essa realidade é uma questão posta à sociedade em geral, mas em especial, aos gestores públicos, tendo em vista a dimensão de suas ações e responsabilidades representativas.

Nesse contexto, poderia-se dizer que vivemos em "tempos de grandes novidades" para as escolas brasileiras. A oportunidade de construção e reconstrução das propostas pedagógicas das escolas que aderem ao Projeto Mais Educação e promovem jornadas escolares em tempo ampliado ou em tempo integral, promove uma oportunidade de integração e debate comunitário, bem como uma reavaliação do próprio sentido social das instituições escolares. $\mathrm{O}$ tempo social destinado à escola passa por um processo de mudança, e como tal, pressupõe um grande número de incertezas para a superação de um modelo de organização escolar tradicional e que, de forma evidente, não tem cumprido, de forma plena, as demandas de uma sociedade em acelerado processo de desenvolvimento e que necessita de cidadãos preparados para compreender e agir em situações cada vez mais complexas.

Parece-nos que essa é uma discussão que não pode ser levada de maneira inflexível, pois cada uma das hipóteses apontadas em forma de perguntas, assim como outras, poderia justificar a ampliação da jornada escolar. No entanto, para pensar em políticas públicas de estado ou de governo, é preciso ter presente essas possibilidades para definir o perfil executivo das ações, ou seja, é preciso ter clareza do contexto em que emergem as necessidades e quais as suas possibilidades de superação.

No ano de 2010, deu-se prosseguimento ao projeto de pesquisa "Educação Integral em Tempo Integral no Ensino Fundamental: concepções e práticas na educação brasileira", que procurava analisar as experiências de Educação Integral ou experiências de ampliação das jornadas escolares na região sul do Brasil. O levantamento de dados foi realizado em escolas de três municípios da região sul do Brasil, nomeadamente, Porto Alegre, Joinville e Apucarana. Durante o trabalho de campo foram realizadas entrevistas individuais e coletivas com professores, pais, alunos entre outros agentes envolvidos de forma direta ou indireta no processo. Com base nos resultados obtidos, a partir da discussão dos dados, a seguir se apresentam indícios representativos sobre as implicações e novos sentidos que emergem dessa realidade, que as escolas estudadas estão vivenciando e atribuindo diferentes significados, de acordo com os seus condicionantes, possibilidades e expectativas.

Primeiramente, tomando por base a experiência do município de Apucarana, alguns aspectos importantes da proposta de educação em tempo integral foram levantados, dentre eles se poderiam destacar como avanços:

A presença da comunidade nos espaços escolares pode ser considerada um aspecto normal no cotidiano escolar, todavia, nessas experiências foi possível 
notar uma intensificação da participação da comunidade em diversos momentos. Essa participação da comunidade, inclusive no planejamento das atividades pedagógicas, em função dos objetivos pretendidos pela proposta de educação em tempo integral, certamente agrega novas perspectivas ao próprio sentido da escola. Para Fernadez Enguita (2001) o afastamento entre a escola e seu entorno social, com suas respectivas necessidades, é um processo que vem se mostrando progressivo e crescente, pois, cada vez mais, as famílias se organizam de maneira menos convencional e estruturada. Assim, nas experiências analisadas, vemos alternativas favorecedoras para as comunidades, pois também, muitas vezes, as ruas têm se convertido em espaços de incerteza e perigo e a escola em espaço favorecedor para a convivência.

Com base no que foi destacado anteriormente, se poderia dizer que há necessidade de repensar diferentes aspectos que compõem a proposta, dentre eles o papel e as funções que desempenham os professores, as famílias, os gestores públicos ou os gestores escolares, já que a ampliação das jornadas escolares anuncia inovações no campo educativo, e como tal, merece um olhar pedagógico para sua melhor compreensão.

Por outro lado, no caso do município de Apucarana, a ampliação das jornadas escolares foi uma proposta implementada em toda a rede municipal e contou com o apoio de várias instâncias da administração pública. Esse dado aponta para a possibilidade de formação de uma rede de responsabilidades dentro das administrações para colaborar na qualificação do processo de escolarização da população. Nesse sentido, além da ação administrativa educacional, é evidente a preocupação latente percebida no discurso de professores, gestores e coordenadores pedagógicos com a qualificação do tempo vivido pelos estudantes em sua permanência na escola.

A superação do uso de expressões como "contraturno", conforme destaca o depoimento do secretário de educação do município de Apucarana, pode ser considerado um aspecto positivo sobre o entendimento da concepção de Educação Integral, pois, segundo ele, "não existe mais essa divisão em dois turnos, quase como se fossem duas escolas, uma escola séria e a escola da brincadeira".

Em todas as experiências analisadas é possível notar que o caminho se distribui entre avanços e novos desafios que emergem da complexidade das ações e do contexto. Nessa conjuntura, um aspecto que merece destaque é o fato de que as atividades propostas ainda são muito vinculadas ao que o professor pode oferecer como alternativa fora das atividades de ensino propriamente ditas, considerando, inclusive, as habilidades para desenvolver atividades artesanais que têm sido utilizadas como alternativa.

Também foi possível perceber a necessidade de melhorias na estrutura física das escolas, pois a ampliação da jornada escolar e a diversificação das 
atividades demandam outros espaços de trabalho para professores e para os estudantes. Por outro lado, é preciso considerar que nessa experiência houve uma preocupação em esclarecer e discutir a ideia de Educação Integral com as comunidades paralelamente com a construção e adaptação dos espaços escolares.

No município de Joinville, outros aspectos importantes foram identificados e analisados para compreensão do contexto e da experiência. Vale destacar que nesse município, as escolas visitadas se localizam na zona rural e apresentam algumas particularidades decorrentes dessa condição. Assim, com base na análise da experiência do município de Joinville, alguns aspectos importantes da proposta de educação em tempo integral poderiam ser destacados como possíveis no que se refere ao desenvolvimento da experiência.

Durante as entrevistas realizadas com professores e gestores escolares, foi possível perceber o esforço de todos para criar condições de trabalho favoráveis e adequar os horários de trabalho dos professores para qualificar o tempo de permanência dos mesmos e dos estudantes nas escolas. Além disso, estratégias pedagógicas inovadoras foram adotadas no planejamento das atividades escolares, sem desprezar as peculiaridades e as características particulares das escolas de zona rural.

A ampliação da jornada escolar demandou uma aproximação das escolas com outros grupos comunitários e uma consequente ampliação da rede de contatos e cooperação das escolas. Essa dinâmica fortaleceu a conjuntura de relações interinstitucionais entre as escolas e as igrejas, associações ou ONGs e, em consequência, agregou outras lógicas às propostas político-pedagógicas das escolas.

Como possíveis desafios para a continuidade da ampliação das jornadas escolares seria possível citar que mesmo existindo uma preocupação com o aprimoramento de diversos aspectos da experiência, a ação ainda se restringe a algumas escolas rurais da rede municipal de ensino e precisaria ser avaliada para implementação em escolas localizadas na zona urbana do município.

A realidade encontrada no município de Porto Alegre proporcionou uma nova oportunidade de compreensão das possibilidades de ampliação da jornada escolar na perspectiva da Educação Integral. Nesse sentido, poderíamos destacar os seguintes avanços que emergem dessa experiência: as escolas possuem uma grande articulação com diferentes instituições ou projetos e essa realidade oportuniza uma grande diversidade de atividades a serem oferecidas aos estudantes; as parcerias com instituições como a Fundação Ronaldinho Gaúcho ou com o Esporte Clube Internacional enriquecem as experiências educativas dos alunos e agregam investimentos materiais (transporte, por exemplo) ao desenvolvimento da proposta pedagógica da escola; as escolas desenvolvem um número significativo e diversificado de projetos próprios, contando com a qualificação e a iniciativa de diversos professores. Esse conjunto de inovações 
qualificam e diversificam a proposta formativa ofertada pelas escolas e isto pode ser considerado positivo para o desenvolvimento da aprendizagem dos estudantes a partir de uma oferta de ensino diversificada.

Como possíveis desafios para o desenvolvimento da proposta, poderia-se comentar que embora exista uma proposta de ampliação das jornadas escolares, ainda há uma necessidade de adequação da carga horária e da oferta de uma jornada única - em que os estudantes tenham a oportunidade de permanecer na escola no horário de almoço - para promover maior aproximação da concepção de educação em tempo integral.

Mesmo que seja evidente o esforço institucional de todos os envolvidos para atender o máximo possível de estudantes em jornada escolar ampliada, em especial, para aqueles que apresentam mais dificuldades de aprendizagem ou estão em situação de vulnerabilidade social, as escolas ainda não conseguem atender a todos. Essa realidade anuncia e denuncia a necessidade de avanços de ordem estrutural, organizativa e pedagógica nas unidades escolares.

$\mathrm{O}$ fato das propostas escolares analisadas no município de Porto Alegre não se ajustarem a algumas exigências da proposta do Programa Mais Educação e de Educação Integral do Ministério da Educação dificulta, ou até mesmo inviabiliza, o recebimento de recursos que seriam previstos para o aumento de oferta da merenda escolar, contratação de pessoal especializado para orientar atividades e transporte de estudantes e isto é um aspecto que precisa ser problematizado junto aos gestores públicos, profissionais da área educacional, família e estudantes.

\section{Considerações Finais}

A ampliação do tempo educativo e o uso de diferentes espaços pedagógicos pela escola envolvem uma série de nuances que merecem ser aprofundadas e reinterpretadas a luz do diálogo entre aspectos empíricos e teóricos. Assim, ao final desta análise sobre as questões relacionadas à ampliação do tempo escolar, vale lembrar que se trata de pensar, além do sentido do tempo diário de permanência dos alunos na escola, também na forma como os processos socializadores e educativos são orientados pela proposta pedagógica das escolas e pelas instituições parceiras. Esse processo, por suas características e complexidades, pressupõe a reorganização e a ressignicaficação do tempo social utilizado pela escola, considerando suas lógicas pedagógicas, sequencial e simbólica na relação com as demandas sociais para a formação de sujeitos capazes de agir em sociedades democráticas e cada vez mais complexas. 
O controle do tempo converteu-se em um dos grandes reguladores da existência humana e, como tal, merece atenção das pesquisas desenvolvidas no campo educativo-pedagógico. Nessa tessitura, o conjunto dos tempos sociais, educativos e, em particular, dos tempos educativo-escolares adquirem um protagonismo especial, ainda mais para países como o Brasil, que vive uma fase de mudanças em seu padrão de desenvolvimento e que demanda rápida melhora nos resultados de aprendizagem de sua população escolar.

Trata-se de um debate que precisa ser posto a toda sociedade e mediado pelos responsáveis pelo planejamento e efetivação das políticas públicas, já que o tempo escolar ocupa um espaço concreto na vida de crianças e adolescentes, condicionando a rotina familiar e as possibilidades de convívio no tempo extraescolar. Horários e calendários escolares materializam intenções político-ideológicas, compõem os traços identitários de uma cultura pedagógico-escolar e se inscrevem no conjunto dos tempos de existência do ser humano em sociedade, merecendo, por conseguinte um compromisso amplo de diferentes agentes sociais.

Mais do que pensar em horários, neste texto, o desafio se materializou na necessidade de pensar em horas concretas, em períodos de permanência dos estudantes nas comunidades escolares e no sentido que essa presencialidade adquire para os envolvidos nesse processo. Seguramente, seria ingênuo resumir o debate sobre o uso do tempo escolar a uma mera revisão de horários ou calendários, pois esse processo envolve uma maior amplitude de implicações que precisam ser aprofundadas nas políticas públicas de educação e no próprio cotidiano das instituições, já que há um vasto campo a ser aprofundado desde diferentes perspectivas.

\section{REFERÊNCIAS}

CARDÚS, S. Propostes d'intervenció per a la conciliació d'horaris familiars, escolars i laborals: informe final. Barcelona: Generalitat de Catalunya-Departament de Benestar i Família, 2003.

CAVALIERE, A. M. Tempo de escola e qualidade na educação pública. Revista Educação e Sociedade, Campinas, v. 28, n. 100 - Especial, p. 1015-1035, out. 2007. Disponível em: $<$ http://www.cedes.unicamp.br $>$. Acesso em: 15/4/2010.

FERNÁNDEZ ENGUITA, M. La jornada escolar. Análisis y valoración de los procesos, los efectos y las opciones de la implantación de la jornada continua. Barcelona: Ariel, 2001. 
GIMENO SACRISTÁN, J. El valor del tiempo en educación. Madri: Ediciones Morata, 2008.

IMBERNÓN, F. As comunidades de aprendizagem e o novo papel do professor. Revista Pátio, n. 51: Educação Integral, ano XIII, p. 8-11, ago./out., 2009.

MORÁN DE CASTRO, C. A xornada escolar na vida cotiá da Infancia: análise da incidencia das modalidades de sesión "partida-única" nos procesos de socialización infantil en Galicia. Tese (Doutorado) - Universidade de Santiago de Compostela, Santiago de Compostela, 2005.

VÁZQUEZ RECIO, R. Las metáforas: una vía posible para comprender y explicar las organizaciones escolares y la dirección de centros. REICE. Revista Electrónica Iberoamericana sobre Calidad, Eficacia y Cambio en Educación, v. 5, n. 3. Disponível em: $<$ http://www.rinace.net/vol5num3.htm>. Acesso em: 30/3/2010.

Texto recebido em 18 de março de 2012 .

Texto aprovado em 22 de abril de 2012. 
